evaluation of subtle, potentially permanent brain dysfunction from low level $\mathrm{CO}$ poisoning will be discussed.

\section{A CASE OF RUPTURED CORNUAL ECTOPIC PREGNANCY: EMERGENCY MANAGEMENT}

\author{
Javier A. Pero, M.D., Lima, Peru
}

A 29 year old female was brought into the ED* because she had fainted after complaining of intense lower abdominal pain and vomiting. We found her awake, slightly confused, weak, pale, sweating, tachycardic and complaining of generalized abdominal pain. Upon questioning her, she told us she had missed her menstrual period for the past 3 months and she'd had a laparotomy 3 years ago with left salpinguectomy and appendectomy because of an ectopic tubal pregnancy. She also had a normal pregnancy with vaginal delivery 10 months ago and wasn't using any contraceptive method. The PE showed signs of hypovolemia and a distended and very tender abdomen, painful in the low half and sides. The BP was $100 / 50$ and pulse 100 . Our first impression was that of a ruptured ectopic pregnancy so a large bore IV line was started with fluids, blood samples drawn for $\mathrm{H} / \mathrm{H}$ and cross-match for 2 units of whole blood. The $\mathrm{H} / \mathrm{H}$ was $22 / 7.4$ so another line was started for transfusion. IM analgesics were provided. The gynecologist on-call arrived 30 minutes later and made an abdominal sonogram which showed a fetus without signs of activity outside the uterus and a good amount of free fluid inside the abdominal cavity. The margins of the uterus weren't clear. The OR was prepared for a laparotomy and the anesthesiologist called.

Five hours after her arrival at the ED the patient was stabilized and in the OR. The findings were: about 1,500 cc of blood and clots; a dead male fetus 12 weeks old; placenta and membranes, all of them free in the abdominal cavity. The uterus was large $(15 \mathrm{~cm})$, with a right cornual rupture. An hysterectomy and irrigation were done. The patient stayed with IV line 1 day, analgesics and cephalosporins 2 days. Discharged after 4 days feeling well. Evolution fine.

* 100-bed private community hospital, an ED with ER physician, nurse staff, attendings on-call and X-ray, lab and OR technicians 24 hours.

\section{PARAMEDICS AREN'T (ALWAYS) NECESSARY}

\author{
Harry F. Oxer, M.D., Belmont, Australia
}

Provision of a paramedic service may not be the most effective way to provide prehospital care, even in a large city.

In Perth, Western Australia, a city of a million people, a needs analysis was performed. This identified the type of case carried, frequency of severe injury or illness, and the skills needed to care for these patients.

The most cost-effective way for Perth is to provide all ambulance crews with selected Advanced Life Support (A.L.S.) skills.

This is economic in terms of training, skills maintenance and equipment, and results in an effective prehospital care system.

Seatbelt laws and motorcycle helmet laws decrease greatly the amount and severity of blunt trauma. Very infrequent recourse to knife or gun as a means of settling arguments means that there is little acute penetrating trauma. These two factors produce a large reduction in the number and percentage of serious trauma, and alter the balance of care skills needed.

\section{RESUSCITATION EQUIPMENT FOR THE PREHOSPITAL ENVIRONMENT}

\section{T. Michael Moles, M.D., Hong Kong}

The delivery of basic and advanced life support within prehospital immediate care systems, field medical and office dental practice are currently being subjected to very radical research, analysis and development.

There is a concurrent need for similar scrutiny of life support technology in order to complement such development. Evaluations of performance and "learner and user friendliness" of life support equipment have been collated and augmented: oral and nasopharyngeal airways; endotracheal and cricothyrotomy apparatus, including the laryngeal obturator; respiratory support equipment; cervical, spinal and limb splinting devices and circulatory and 